\title{
ARTICLE OPEN Molecular evidence of synaptic pathology in the CA1 region in schizophrenia
}

\author{
Natalie Matosin ${ }^{1,2,3}$, Francesca Fernandez-Enright ${ }^{2,4}$, Jeremy S Lum², Martin Engel ${ }^{2}$, Jessica L Andrews ${ }^{2}$, Nils C Gassen ${ }^{1}$, \\ Klaus V Wagner ${ }^{1}$, Mathias V Schmidt ${ }^{1}$ and Kelly A Newell ${ }^{2}$
}

\begin{abstract}
Alterations of postsynaptic density (PSD)95-complex proteins in schizophrenia ostensibly induce deficits in synaptic plasticity, the molecular process underlying cognitive functions. Although some PSD95-complex proteins have been previously examined in the hippocampus in schizophrenia, the status of other equally important molecules is unclear. This is especially true in the cornu ammonis (CA) 1 hippocampal subfield, a region that is critically involved in the pathophysiology of the illness. We thus performed a quantitative immunoblot experiment to examine PSD95 and several of its associated proteins in the CA1 region, using post mortem brain samples derived from schizophrenia subjects with age-, sex-, and post mortem interval-matched controls ( $n=20 / g$ roup). Our results indicate a substantial reduction in PSD95 protein expression (-61.8\%). Further analysis showed additional alterations to the scaffold protein Homer1 (Homer1a: $+42.9 \%$, Homer1b/c: $-24.6 \%$ ), with a twofold reduction in the ratio of Homer1b/c:Homer1a isoforms $(P=0.011)$. Metabotropic glutamate receptor 1 (mGluR1) protein levels were significantly reduced $(-32.7 \%)$, and Preso, a protein that supports interactions between Homer1 or PSD95 with mGluR1, was elevated (+83.3\%). Significant reduction in synaptophysin $(-27.8 \%)$ was also detected, which is a validated marker of synaptic density. These findings support the presence of extensive molecular abnormalities to PSD95 and several of its associated proteins in the CA1 region in schizophrenia, offering a small but significant step toward understanding how proteins in the PSD are altered in the schizophrenia brain, and their relevance to overall hippocampal and cognitive dysfunction in the illness.
\end{abstract}

npj Schizophrenia (2016) 2, Article number: 16022; doi:10.1038/npjschz.2016.22; published online 29 June 2016

\section{INTRODUCTION}

The hippocampus is a region of the brain highly implicated in schizophrenia pathology, with reports from several laboratories consistently showing altered hippocampal form, volume, and function in the illness. ${ }^{1}$ This region, and especially the cornu ammonis (CA) sub regions, are crucial for cognitive functions that are weakened in individuals with schizophrenia. ${ }^{2}$ Healthy cognitive functions are largely dependent on dynamic changes in synapse configuration in the CA1 subfield, an important component of the hippocampus, which predominantly functions to consolidate inputs from CA3. ${ }^{3}$ This process of synaptic plasticity depends on the coordinated molecular activity of several proteins packed tightly into the postsynaptic density (PSD), with disruption to these molecules hypothesized to predispose neurons to synaptic deficits. ${ }^{4}$ Members of the PSD, particularly PSD95 and those with which it forms a complex, are thus of increasing interest for improving our understanding of the molecular processes underlying memory impairments and hippocampal pathology in schizophrenia.

PSD95 is the most abundant protein at the PSD. It is a member of the membrane-associated guanylate kinase family, a group of proteins that have prominent roles in synaptic plasticity. ${ }^{5}$ Consistent with this role, PSD95 is critical for molecular organization of the PSD ${ }^{6}$ and synapse stabilization. ${ }^{7}$ Previous studies have analyzed PSD95 expression in multiple regions of brains from patients with schizophrenia, although the results of these studies could be considered inconclusive; within many regions, the data are conflicting with either no change, increased, or decreased PSD95 mRNA or protein reported across cortical (e.g., dorsolateral prefrontal cortex) and subcortical (e.g., thalamus, nucleus accumbens, striatum) regions. ${ }^{8-18}$ Specifically within the hippocampus, studies have either detected increased PSD95 protein levels in the CA3 region of schizophrenia subjects, ${ }^{19}$ or no change in protein or transcript expression in CA1, CA4, the parahippocampal gyrus and dentate gyrus. ${ }^{8,9,19-21}$ Still, alterations of other important PSD95complex scaffold proteins in CA1 that could contribute to synaptic pathology in schizophrenia cannot be excluded. For example, decreased levels of the critical scaffold protein Homer 1 were reported in an unspecified region of the hippocampus, ${ }^{22}$ and increased levels of its related multi-scaffolding protein, Tamalin, was detected in CA1 in schizophrenia subjects. ${ }^{23}$ Preso proteins have a similar role as Tamalin; ${ }^{24,25}$ these proteins have been shown to be decreased in the dorsolateral prefrontal cortex in schizophrenia, ${ }^{26}$ but their status in the hippocampus in schizophrenia remains unknown.

In addition to its organizational role, PSD95 is one of the most stable proteins at excitatory glutamate synapses. ${ }^{27,28}$ PSD95 is a major regulator of protein-protein interactions, which is important for processes such as intracellular trafficking, cell-surface expression, recycling, and activity of ionotropic and group I metabotropic glutamate receptors (mGluRs), mGluR1 and mGluR5..$^{29,30}$ These

${ }^{1}$ Departments of Translational Research in Psychiatry and Stress Neurobiology and Neurogenetics, Max Planck Institute of Psychiatry, Munich, Germany; ${ }^{2}$ Departments of Science, Medicine and Health, and Social Sciences, Illawarra Health and Medical Research Institute, University of Wollongong, Wollongong, NSW, Australia; ${ }^{3}$ Department of Medicine, School of Psychiatry, University of New South Wales, Sydney, NSW, Australia and ${ }^{4}$ Department of Health Science, School of Science, Australian Catholic University, Brisbane, QLD, Australia.

Correspondence: N Matosin (natalie_matosin@psych.mpg.de)

Received 7 February 2016; revised 21 May 2016; accepted 23 May 2016 
processes occur in concert with several other important scaffolding proteins, including Homer1 and Tamalin. ${ }^{29-31}$ Previously detected changes in Homer1 and Tamalin in the schizophrenia hippocampus $^{22,23}$ might be related to alterations to glutamate transmission (specifically via mGluR activity), protein-protein interactions, trafficking, and gene expression, contributing to glutamate dysregulation which is apparent in the disorder. Indeed, recent studies have shown disruptions to NR2B subunit-containing $N$-methyl- $D$-aspartate receptors and a-amino-3-hydroxy-5-methyl-4-isoxazolepropionic acid receptors in the CA3 in schizophrenia, ${ }^{19}$ and accordingly, we recently found evidence of increased mGluR5 protein levels in the CA1 region of schizophrenia subjects relative to controls. ${ }^{23}$ It is unclear whether this finding extends to mGluR1, which has not been examined in the hippocampus in schizophrenia, although increased mGluR1a mRNA and protein levels have been previously reported in the prefrontal cortex of schizophrenia patients. ${ }^{32,33}$

Despite a recent report that disruptions to molecules in the PSD, such as PSD95 and NR2B subunit-containing $N$-methyl- $D$-aspartate receptors are specific to $C A 3$ and not CA1 in schizophrenia, ${ }^{19}$ our previously reported alterations of mGluR5 and Tamalin in $C A 1^{23}$ suggest that disruptions to other important PSD95-complex molecules may exist in the CA1 region in schizophrenia. In addition, there is extensive evidence implicating CA1 in the illness; this includes reduced CA1 volume in first-episode schizophrenia patients, ${ }^{34}$ deformity of CA1 being related to symptom severity and antipsychotic response, ${ }^{35}$ and evidence that the CA1 subfield is hyperactive in the disorder. ${ }^{36}$ These studies point towards dysregulation of the molecules that comprise this region. We therefore aimed to explore the possibility that molecular abnormalities to important PSD95-complex proteins occur in CA1 by conducting a quantitative immunoblot study in a well-characterized post mortem brain cohort. We examined PSD95, Homer1 (short [Homer1a] and long [Homer1b/ c] isoforms), Preso and mGluR1 proteins. Furthermore, levels of the presynaptic protein synaptophysin were assessed, as this protein has been shown to be a marker of synaptic density. ${ }^{37}$

\section{RESULTS}

PSD95

PSD95 is a major postsynaptic scaffold protein in the PSD, and aberrations in this protein can lead to deleterious effects on molecular synchronization in the PSD and synaptic plasticity. ${ }^{6,7}$ PSD95 was detected at the expected molecular weight of $95 \mathrm{kDa}$ using immunoblot. Our results showed that PSD95 protein levels were significantly reduced in schizophrenia subjects compared with controls, after co-varying for brain $\mathrm{pH}$ and post mortem interval ( $-61.84 \% ; F_{1,34}=24.985, P<0.001$; Figure 1a); these were variables associated with PSD95 protein levels (brain $\mathrm{pH}: r=$ $-0.331, P=0.042$ in all subjects and $r=-0.542, P=0.017$ in controls; post mortem interval: $r=0.544, P=0.016$ in schizophrenia subjects; Supplementary Table 1). There were no effects of hemisphere or illness duration on PSD95 protein measures, and no correlation with lifetime antipsychotic drug medication estimates. However a significant effect of antidepressant medication was seen for PSD95 (yes $n=12 ; \mathrm{t}_{17}=3.289, P=0.005,-44.5 \%$ ).

\section{Homer1a and Homer1b/c}

Homer1 is a major scaffold protein of the PSD, which is known to have a role in the regulation of dendritic spine morphology and synaptic function in hippocampal neurons. ${ }^{38}$ To assess protein levels of Homer1 in the CA1 region in schizophrenia, the two main splice variants of Homer1 were measured using antibodies specific for Homer1a (short isoforms, an early immediate gene which acts as a dominant negative for the Homer1 long isoforms) and Homer1b/c (long isoforms, which are expressed constitutively). These proteins were detected at the expected molecular weights (Homer1a: $30 \mathrm{kDa}$, Homer1b/c: $40 \mathrm{kDa}$ ). A significant increase in protein levels of Homer1a was detected in schizophrenia subjects relative to controls, after co-varying for freezer storage time $\left(+42.92 \% ; F_{1,34}=9.751, P=0.004\right.$; Figure $\left.2 a\right)$, which was a variable that correlated with Homer1a protein expression in control subjects only $(r=0.545, P=0.013$; Supplementary Table 1$)$. Conversely, Homer $1 \mathrm{~b} / \mathrm{c}$ levels were significantly reduced, after co-varying for freezer storage time $\left(-24.55 \%, F_{1,34}=4.810\right.$, $P=0.035$; Figure $2 \mathrm{~b}$ ), which correlated with Homer1b/c levels in all subjects $(r=-0.341, P=0.039$, Supplementary Table 1). These aberrations in Homer1a and Homer1b/c protein levels resulted in a significant twofold decrease in the ratio of Homer $1 \mathrm{~b} / \mathrm{c}$ to Homer1a from $29.11 \pm 18.19$ to $15.12 \pm 13.50 \quad\left(t_{35}=-2.679\right.$, $P=0.011)$, suggesting an imbalance of these proteins in schizophrenia. There were no effects of hemisphere on Homer1
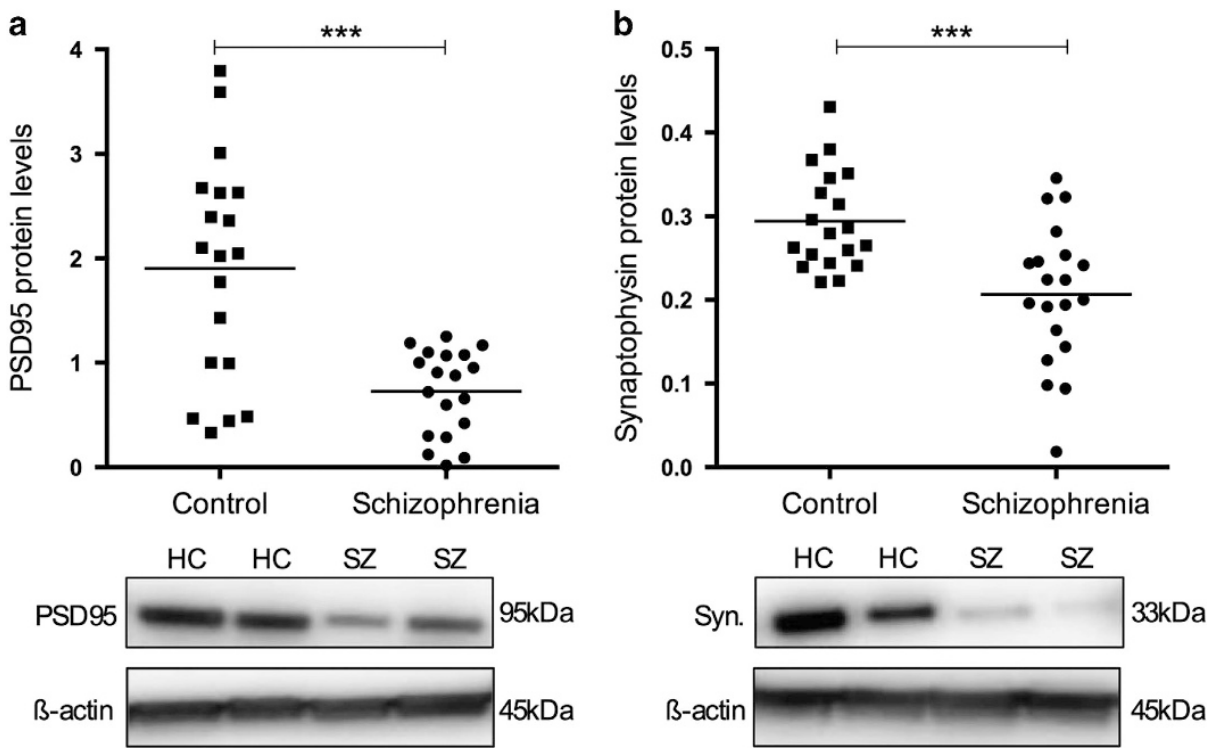

Figure 1. Scatterplots depicting normalized protein levels of (a) PSD95 and (b) synaptophysin in the CA1 region of healthy control (HC) and schizophrenia (SZ) subjects. Raw means (before co-varying the data) are depicted. ${ }^{* *} P<0.001$. 
a

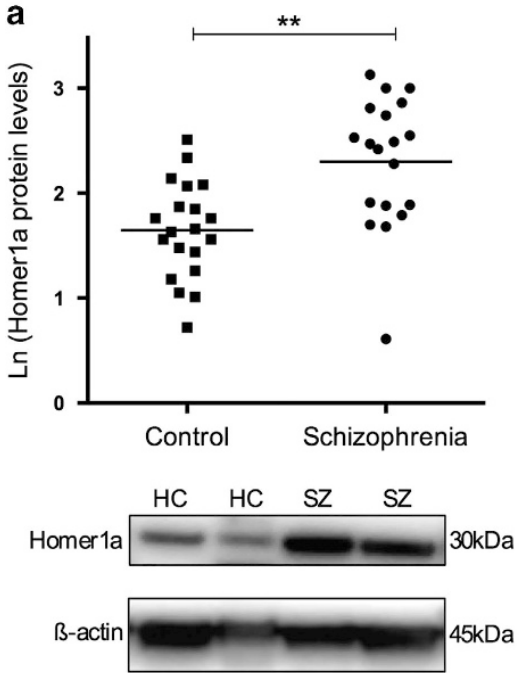

b
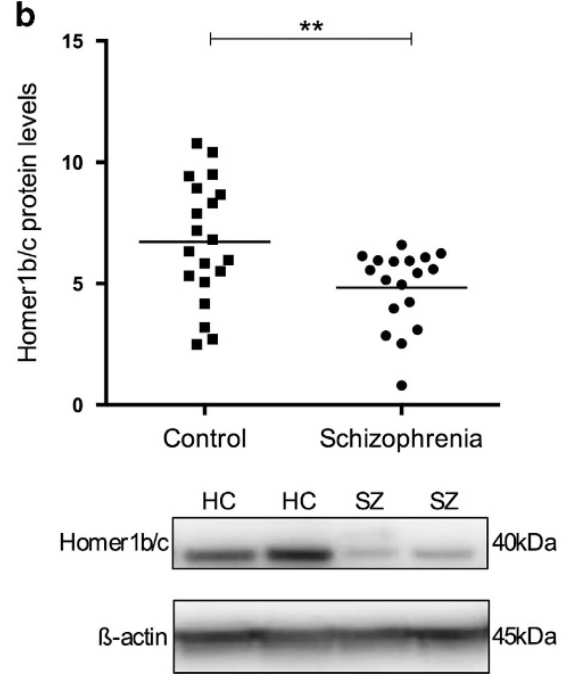

C
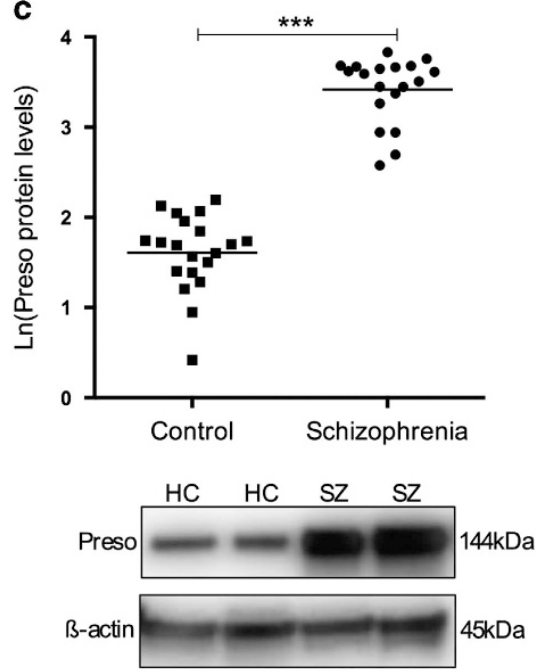

Figure 2. Scatterplots depicting normalized protein levels of (a) Homer1a, (b) Homer1b/c, and (c) Preso, in the CA1 region of healthy control (HC) and schizophrenia (SZ) subjects. Raw means (before co-varying the data) are depicted; Homer1a and Preso are depicted in the natural logarithm form owing to abnormal distribution of the data. ${ }^{* *} P<0.01,{ }^{* *} P<0.001$.

measures, and no correlation with lifetime antipsychotic drug medication estimates, or illness duration. However, a significant effect of antidepressant medication was seen on Homer $1 \mathrm{~b} / \mathrm{c}$ levels (yes $n=11 ; \mathrm{t}_{15}=2.950, P=0.010,-22.5 \%$ ).

\section{Preso}

Preso proteins facilitate PSD95/Homer1 long-isoform interactions with group I mGluRs, and reportedly have a role in dendritic spine morphogenesis. ${ }^{24,25}$ Considering the aforementioned alterations of PSD95 and Homer1, we additionally assessed protein levels of Preso in the CA1 region in schizophrenia. Preso was detected at the expected molecular weight of $144 \mathrm{kDa}$. Preso protein expression was significantly higher in schizophrenia subjects compared with controls (+83.30\%; $t_{37}=14.142, \quad P<0.001$; Figure 2c). There were no effects of sample characteristics (age at death, $\mathrm{pH}$, post mortem interval, RNA integrity number (RIN), brain weight, and freezer storage time) on Preso protein levels, or effects of hemisphere, antidepressant, or lifetime antipsychotic drug medication estimates. However, Preso protein levels were associated with age of disease onset in schizophrenia subjects $(r=0.498, P=0.030)$.

\section{mGluR1}

mGluR1 is a key modulator of glutamatergic neurotransmission and synaptic plasticity, and its activity and trafficking is regulated by Homer1 and PSD95 via protein-protein interactions in the PSD. ${ }^{30}$ mGluR1 was detected at two molecular weights, thus monomer $(150 \mathrm{kDa})$, dimer $(250 \mathrm{kDa})$, and total (sum of monomer and dimer) levels are reported to assess protein levels of mGluR1. Total mGluR1 protein levels were significantly lower in schizophrenia subjects relative to controls maintained after co-varying for post mortem interval (-32.65\%; $F_{1,30}=14.586, P=0.001$; Figure 3a). Similarly, levels of mGluR1 monomer were reduced by $-67.22 \%\left(F_{1,33}=49.489, P<0.001\right.$, Figure $\left.3 b\right)$ and mGluR1 dimer by $-66.41 \%$ (dimer: $F_{1,33}=60.885, P<0.001$; Figure $3 c$ ), after also co-varying for post mortem interval, which was significantly correlated with all mGluR1 measures (Supplementary Table 1). There were no effects of hemisphere, illness duration, antidepressant, or lifetime antipsychotic drug medication estimates on mGluR1 proteins.

\section{Synaptophysin}

Prior studies have shown that levels of synaptophysin are a reliable marker of synaptic density. ${ }^{37}$ Synaptophysin was thus also assessed using immunoblot, to determine whether the molecular alterations observed in the CA1 region in schizophrenia might extend to deficits in synapse numbers. Synaptophysin was detected at the expected molecular weight of $33 \mathrm{kDa}$. Protein levels of synaptophysin were significantly reduced in schizophrenia subjects compared with controls (-27.84\%; $t_{36}=-3.558, P=0.001$; Figure 1b). There were no effects of sample characteristics (age at death, $\mathrm{pH}$, post mortem interval, RIN, brain weight, and freezer storage time) on synaptophysin protein levels, or effects of hemisphere, age of disease onset, antidepressant, or lifetime antipsychotic drug medication estimates.

Protein-protein associations in schizophrenia relative to controls To assess the hypothesis of abnormal protein-protein interactions at the synapse in schizophrenia, we ran exploratory analyses to assess the correlations between Group I mGluRs with these scaffold proteins (note that protein levels of mGluR5 and Tamalin were drawn from our previous work ${ }^{13}$ ). In controls, mGluR1 total levels were significantly correlated with PSD95 $(r=0.612, P=0.012)$ and Homer1a $(r=-0.654, P=0.004)$, whereas mGluR1 monomer levels were correlated with Homer1a $(r=-0.612, P=0.005)$ and Homer1b/c $(r=0.549, P=0.015)$. mGluR1 dimer correlated with PSD95 $(r=0.530, P=0.020)$; all these associations were not detected in the schizophrenia group. mGluR1 monomer levels were significantly associated with Tamalin in control subjects $(r=0.500, P=0.029)$ but not schizophrenia subjects, whereas mGluR1 total levels were associated with Tamalin in schizophrenia subjects $(r=0.526, P=0.036)$, but did not reach significance in controls $(r=0.463, P=0.061)$. No associations of mGluR5 and the scaffold proteins were observed in controls, although mGluR5 monomer and dimer levels were highly correlated with PSD95 $(r>0.621, P<0.005)$ and Tamalin $(r>0.611, P<0.005)^{23}$ in the schizophrenia group. A summary of these results are presented in Table 1, and the complete set of correlations for all other proteins measured in these subjects and regions are included in Supplementary Table 2. 

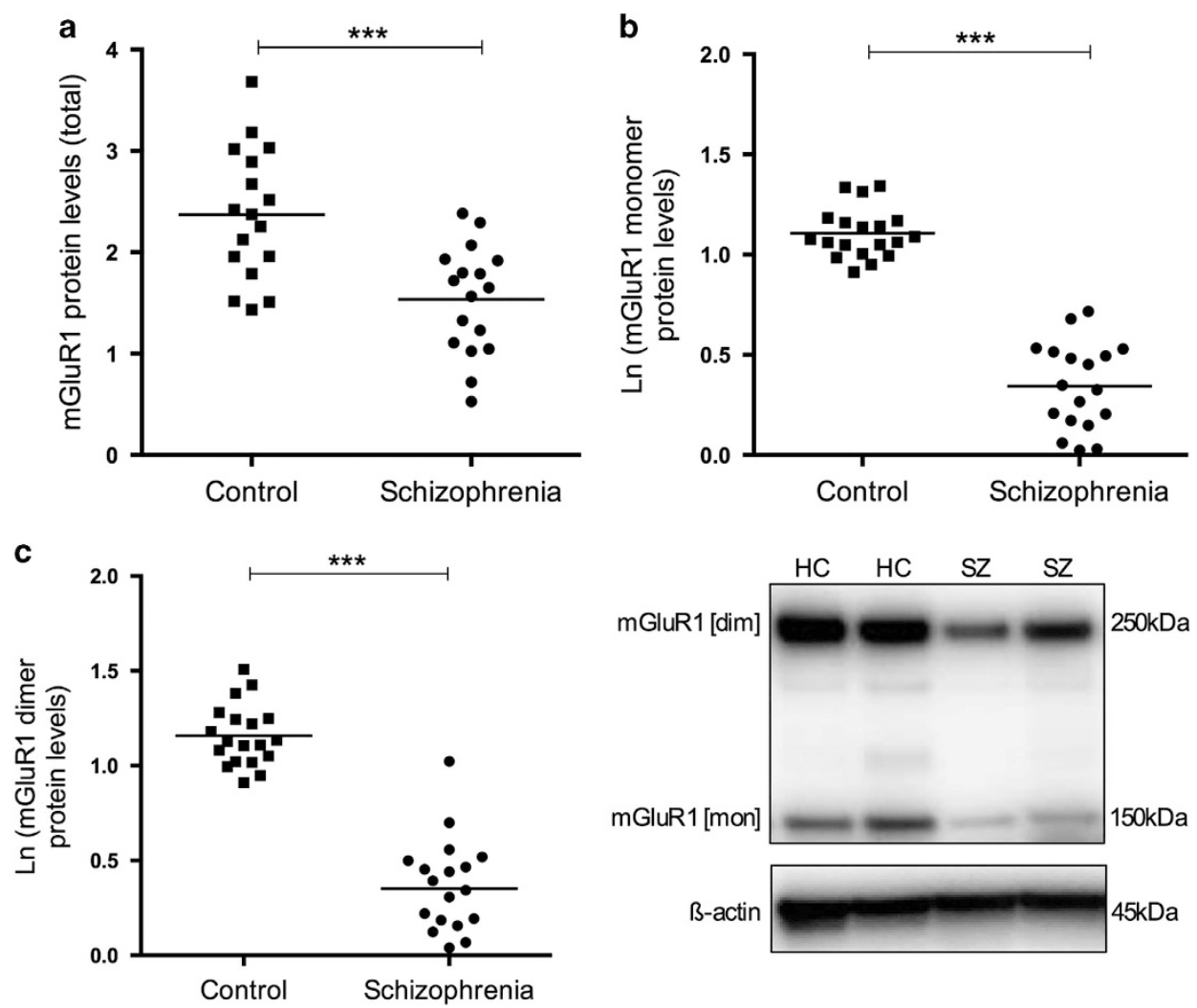

Figure 3. Scatterplots depicting normalized (a) total, (b) monomer, and (c) dimer measures of mGluR1 protein levels in the CA1 region of healthy control $(\mathrm{HC}$ ) and schizophrenia (SZ) subjects. Raw means (before co-varying the data) are depicted; mGluR1 monomer and dimer levels are depicted in the natural logarithm form owing to abnormal distribution of the data. mGluR1 monomer levels were furher transformed $(\operatorname{Ln}[\mathrm{x}]+1)$ to account for negative values. ${ }^{* * *} P<0.001$.

\section{DISCUSSION}

This study shows extensive disruption to PSD95 and several important PSD95-complex proteins in post mortem samples from the CA1 hippocampal region of schizophrenia subjects relative to matched controls. In particular, substantial decreases in PSD95 and synaptophysin were observed, as well as increases and decreases in other related postsynaptic proteins suggesting altered protein-protein interactions in the illness. These data support the currently proposed model of hippocampal dysfunction in schizophrenia, ${ }^{1}$ centered on reduced volume and hyperactivity of the hippocampus which has been consistently reported in the illness. ${ }^{36,39-43}$

Prior mechanistic studies show that PSD95 is required to sustain molecular organization of the PSD ${ }^{6}$ and synapse stabilization. ${ }^{7}$ Deficiencies in PSD95 induced by RNA interference knockdown inflicts widespread deletions of entire segments of the PSD in rat hippocampal neurons, ${ }^{6}$ and impedes normal development of synapse structure and function after synaptic potentiation. ${ }^{7}$ The substantial reduction in PSD95 observed in this study (-62\%) may therefore suggest the existence of deleterious effects to the PSD in the CA1 region in the illness. Similarly, synaptophysin proteins were reduced by almost $30 \%$ in the CA1 region of schizophrenia subjects compared to controls. Considering 95\% of PSD95 protein is localized to synapses ${ }^{44}$ and the levels of synaptophysin and PSD95 strongly correspond to synapse numbers, ${ }^{45,46}$ these data are strongly suggestive of reduced synapse number in the CA1 region of schizophrenia subjects. To our knowledge, there are no studies examining possible changes to synapse density in the CA1 region of the schizophrenia brain, although reductions in gene expression of transcripts associated with dendritic spines has been reported in this region. ${ }^{47}$ In addition, increased spine density of pyramidal cell apical dendrites was reported in the adjacent CA3 region, ${ }^{19}$ which might be compensatory for synaptic alterations in CA1. An extension of this work in CA1 will be important to confirm the molecular findings of the current study and to determine on which synapses in CA1 these deficits are occurring (e.g., Schaffer collaterals), as well as how this fits with the findings in CA3.

The extensive aberrations in other PSD95-complex proteins in this study support the presence of altered synapses and plasticity in CA1 in schizophrenia. It is now established that Homer1 cooperates with PSD95 to form the architectural basis required for PSD receptor clustering and the appropriate signaling in response to prolonged neuronal stimuli. ${ }^{48}$ Upregulation of Homer1a proteins and downregulation of Homer1b/c were observed in this study, resulting in a twofold decrease in the ratio of Homer $1 \mathrm{~b} / \mathrm{c}$ to Homer1a. The relative balance of Homer1b/ c:Homer1a isoforms is considered to be functionally significant in the regulation of plasticity, dendritic spine morphology, and hippocampal-dependent cognitive function, ${ }^{49}$ with our data thus supporting the presence of synaptic dysregulation in CA1 in schizophrenia. Disruption of Homer1 function may also lead to reduced trafficking of group I mGluRs, their coupling to $\mathrm{IP}_{3}$ receptors and calcium homeostasis, which are processes required to appropriately direct plasticity. ${ }^{50}$ The Homer $1 \mathrm{~b} / \mathrm{c}: 1 \mathrm{a}$ ratio is described to act as a molecular switch that redirects signaling through either mGluR1 or mGluR5. ${ }^{51,52}$ mGluR1 protein levels were reduced in this study, suggesting that it has an inverse relationship with mGluR5, which are increased in the same region and subjects. ${ }^{23}$ In addition, Preso and Tamalin, which are proteins that facilitate PSD95/Homer1 long isoforms with mGluR1/5, 24,25,29,31 were also upregulated, potentially in response 
to PSD95/Homer1 downregulation and an imbalance of mGluR1: mGluR5 levels. Preso proteins additionally direct synaptic plasticity by facilitation of the PSD95-complex to filamentous (F)-actin; ${ }^{25}$ overexpression of Preso might thus represent an attempt to reconnect PSD95 and F-actin molecules to repair deficits in plasticity.

A consistent finding in the hippocampus of schizophrenia patients-and CA1 in particular-is increased blood volume, supporting evidence of CA1 hyperactivity in the illness. ${ }^{36,39-43}$ Increased activity of CA1 is hypothesized to arise from deficient GABAergic firing in CA3, causing disinhibition of pyramidal cell inputs and increasing glutamate release onto CA $1 .{ }^{53}$ Although it might be hypothesized that glutamate excitotoxicity leads to neuronal and thus volume loss in this region, the total number of neurons in the hippocampus is unaltered in schizophrenia. ${ }^{54-57}$ A recent immunostaining study however indicates reduced glutamic acid decarboxylase-immunoreactive neuropil density in post mortem schizophrenia hippocampal sections including $C A 1,{ }^{58}$ which could contribute to hippocampal volume loss. In support, small deficits of interneuron populations such as parvalbuminand somatostatin-positive interneurons have been reported in the hippocampus of schizophrenia subjects, ${ }^{55,59-61}$ ostensibly inducing hyperactivity via the disinhibition of pyramidal cells. ${ }^{62}$ It is interesting to note that the reduced levels of mGluR1 proteins in this study were detected with an antibody specific for the mGluR1a isoform, which is exclusively localized to interneurons of the CA1 region. ${ }^{63,64}$ Conversely, mGluR5, which is expressed on CA1 pyramidal neurons, ${ }^{63}$ was increased in the same region and subjects. $^{23}$ The close correlation of mGluR1a and PSD95 seen in controls, but not schizophrenia subjects (Table 1), additionally suggests that the pathological reduction in PSD95 occurs alongside mGluR1a, which is consistent with the loss of interneurons observed in CA1. ${ }^{55,59-61}$

It should also be considered that our findings are in contrast to a recent report of unaltered PSD95 protein levels in the CA1 region in a similar sized schizophrenia post mortem cohort. ${ }^{19}$ Differences in age at death and manner of death may account for these inconsistent findings. However, considering the existence of a rostro-caudal gradient of gene expression in the hippocampus, ${ }^{65,66}$ it is plausible that small differences in dissection procedures and region collected in this study relative to the prior study ${ }^{19}$ have led to cohort-dependent differences and diverging results. Slight anatomical differences between samples may also explain the high levels of variability observed in control subjects in this study for PSD95 and Homer $1 \mathrm{~b} / \mathrm{c}$ protein measures; this finding is opposite to typical observations in previous post mortem studies (i.e., greater spread of results in patients compared with controls). However, PSD95 and Homer 1 proteins are also highly susceptible to activity- and experience-dependent change, ${ }^{67,68}$ especially in the CA1 region which is necessary for proper plastic processes. The spread of PSD95 and Homer1b/c:1a ratio may reflect a normal state, where these proteins are responding well to activity, experience and other stimuli. Alternatively, the lack of spread in schizophrenia subjects may represent an inability of patients to process or react to various stimuli, leading to altered experience- and activity-dependent molecular responses and ultimately disrupted plasticity.

A possible limitation of this study is the confounding effect of medication, as all schizophrenia subjects were medicated with antipsychotic drugs in this study. We did not observe any correlations with our protein measures and antipsychotic drug exposure. Our previous work additionally reports no influence of typical or atypical antipsychotic drug treatment on mGluR5, Preso and Tamalin protein expression in the hippocampus of rats. ${ }^{23,69}$ Others have shown that antipsychotic medication might influence transcript and protein expression of PSD95 and Homer1, but these were in regions other than the hippocampus. ${ }^{70}$ It may be of relevance that we also observed a non-significant borderline 
Table 2. Summary of post mortem subject demography

\begin{tabular}{lcc}
\hline & $\begin{array}{c}\text { Control } \\
(\mathrm{n}=20)\end{array}$ & $\begin{array}{c}\text { Schizophrenia } \\
(\mathrm{n}=20)\end{array}$ \\
\hline Brain pH & $6.6 \pm 0.3$ & $6.6 \pm 0.3$ \\
Post mortem interval (h) & $26.1 \pm 12.8$ & $28.3 \pm 10.1$ \\
RNA integrity number & $7.2 \pm 0.7$ & $7.2 \pm 0.5$ \\
Age at death (years) & $58.2 \pm 12.6$ & $55.5 \pm 13.5$ \\
Gender & $2 \mathrm{~F}, 18 \mathrm{M}$ & $9 \mathrm{~F}, 11 \mathrm{M}$ \\
Hemisphere & $13 \mathrm{R}, 7 \mathrm{~L}$ & $10 \mathrm{R}, 10 \mathrm{~L}$ \\
Age of disease onset (years) & - & $23.5 \pm 6.8$ \\
Duration of illness (years) & - & $32.05 \pm 13.7$ \\
Manner of death (natural/suicide) & $20 / 0$ & $16 / 4$ \\
Lifetime antipsychotic drug & - & $668 \pm 421$ \\
medication (standardized & & \\
chlorpromazine equivalent, mg) & & 12 \\
Antidepressant history (yes/no) & - & \\
\hline
\end{tabular}

Abbreviations: $F$, female; $L$, left; $M$, male; $R$, right.

Data are expressed as mean \pm s.d.

correlation between synaptophysin with lifetime antipsychotic drug exposure, considering the typical antipsychotic Trifluoperazine has been shown to reduce synaptophysin transcript expression within the Schaffer collateral region of CA1. ${ }^{71}$ Furthermore, chlorpromazine equivalents were used as an indicator of antipsychotic drug exposure in this study, which is an approach limited by the high rate of medication noncompliance among patients. ${ }^{72}$ Chlorpromazine equivalents are based on dopamine receptor $D_{2}$ occupancy, which is relevant for typical antipsychotic medication history, but has limited value for patients who have a history of atypical antipsychotic drug exposure. It is also notable that an association of antidepressant drug exposure (yes/no) was observed with protein levels of Homer $1 \mathrm{~b} / \mathrm{c}$ and PSD95. No data exists regarding the effects of antidepressant drug exposure on Homer1 or PSD95 proteins in the hippocampus, although Feyissa et al. $^{73}$ reported no antidepressant effects in the anterior prefrontal cortex.

In summary, this study provides evidence of alterations to important PSD95-complex proteins in the CA1 region in subjects with schizophrenia. These included PSD95, Homer1 long and short isoforms, Preso, mGluR1, synaptophysin, as well as Tamalin ${ }^{23}$ and mGluR5 ${ }^{23}$ proteins, which we have reported previously. Although the mechanisms and morphological effects of these alterations were not explored here, we speculate that there are changes to synaptic plasticity and/or neurophil loss in the CA1 region in schizophrenia, contributing to the increased activity and decreased volume of the hippocampus consistently observed in the disorder. Although the circumstantial support is persuasive these significant molecular leads require follow-up with morphological studies to confirm the existence of aberrant plasticity in the CA1 region in patients with schizophrenia.

\section{MATERIALS AND METHODS}

\section{Post mortem brain samples}

Human post mortem brain samples were from the NSW Brain Tissue Resource Centre (Sydney, NSW, Australia). Samples were derived from the CA1 region of 20 schizophrenia subjects (diagnosed according to the DSMIV) and 20 controls (no history of psychiatric disorder), with these subjects matched according to post mortem interval, tissue $\mathrm{pH}$, age at death, and RIN (Table 2); the sample was adequately powered (0.8-0.9) to detect expression differences (24\%) owing to disease. Specimens were processed and characterized according to Weickert et al., ${ }^{74}$ with samples in this study taken from the same subjects. Regarding dissection procedure, brain tissue was collected and dissected fresh at the level of the geniculate nucleus, and then frozen. From this level of dissection, architecture of the hippocampus could be visually verified and CA1 was manually dissected. When difficulty was encountered in identifying the hippocampal sub regions, tissue was further cryosectioned to confirm anatomical location. All subjects with schizophrenia were prescribed antipsychotics at the time of death and a lifetime chlorpromazine equivalent was calculated for each patient. This study was approved by the Human Research Ethics Committee at the University of Wollongong (HE99/222).

\section{Quantitative immunoblotting}

Relative protein densities were determined by immunoblot analysis as described previously, with minor modifications to increase signal. ${ }^{26}$ Briefly, $5 \mu \mathrm{g}$ of total protein was loaded per subject (blind to diagnosis) and run in duplicate. Probing was performed using the following primary antibodies: PSD95 (1:500, Millipore, Sydney, NSW, Australia, MAB1598); Homer1a (1:100, Santa Cruz, CA, USA, sc-8922), Homer1b/c (1:2000, ab97593, Abcam, Melbourne, VIC, Australia); Preso (1:1000, Santa Cruz, sc-242862); mGluR1 (1:250, Millipore, 07-617); synaptophysin (1:1000, Life Technology, Scoresby, VIC, Australia, 8H2L12 (monoclonal)). Blots were subsequently incubated with horseradish peroxidase-conjugated secondary antibody (antirabbit: 1:1000, Millipore, ap307P) and visualized using enhanced chemiluminescent detection kit (BioRad, Gladesville, NSW, Australia). Band densities were quantified with the Gel Doc 2200 Pro (Carestream Molecular Imaging, Woodbridge, CT, USA) and Carestream Molecular Imaging software (v5.0.4.44, Carestream Molecular Imaging). All proteins were within the linear range of detection for $5 \mu \mathrm{g}$ protein (see Supplementary Information for details). Densitometry values for each sample were normalized to $\beta$-actin (1:5000; MAB1501, Millipore) by dividing protein values by $\beta$-actin values to account for differences in protein loadings between subjects; notably, $\beta$-actin was unaltered across cohorts. ${ }^{23,75}$ Values were subsequently normalized to a pooled sample (consisting of 10 pooled post mortem brain samples, with the same pool used across all experimental runs) to also account for potential gel-to-gel variability.

\section{Statistical analyses}

Statistical analyses were performed with SPSS (Chicago, IL, USA, version 19). Significance was set to $P<0.05$ and data are presented as mean \pm s.e.m. The average of the duplicates for each protein measure was used for statistical analyses. PSD95, Homer1b/c, mGluR1 (total) and synaptophysin protein levels were normally distributed. mGluR1 (monomer) and mGluR1 (dimer) were skewed to the left, while Homer1a and Preso were skewed to the right (Kolmogorov-Smirnov: $d=0.089-0.237 ; P<0.033$ ); normalized distribution for these proteins was achieved by transforming to the natural logarithm of the relative protein values. Outliers were screened as mean \pm 2 s.d. and removed. Two subjects were removed on average from each protein analysis.

Spearman's correlations were implemented to analyze whether sample characteristics (age at death, $\mathrm{pH}$, post mortem interval, RIN, brain weight, and freezer storage time) were associated with protein measures in all subjects and control and schizophrenia subjects individually. Where significant correlations were detected, analyses of covariance were performed to compare schizophrenia and control subjects, with significant correlates taken as covariates; where no significant correlations were detected, analysis was performed using independent $t$-tests. Two-way ANOVAs were used to determine main and interactive effects of diagnosis and brain hemisphere (left/right); gender analyses were not included owing to power constraints. In the schizophrenia group, lifetime antipsychotic drug history, age of disease onset, and duration of illness were also analyzed using Spearman's correlations to extricate any potential effects on the data. Associations with antidepressant exposure (yes/no) with each of the protein levels were assessed using independent $t$-tests. Finally, the potential for differences in protein-protein associations between schizophrenia and controls groups were also assessed using Spearman's correlations.

\section{ACKNOWLEDGMENTS}

J.L.A. and J.S.L. acknowledge Australia Rotary Health for support in the form of an lan Scott Scholarship. NM thanks the Company of Biologists (UK) for their support in the form of a DMM Traveling Fellowship. We extend thanks to the anonymous reviewers, whose comments have improved the final manuscript.

\section{CONTRIBUTIONS}

N.M. was involved in experimental design, performed the experiments, and wrote the manuscript; F.F.-E. provided the tissue samples and technical support, as well as 
reviewed the manuscript. J.S.L., M.E., and J.L.A. performed experiments, provided technical support and reviewed the manuscript. N.C.G. and K.V.W. were involved in experiment optimization, provided technical support, and reviewed the manuscript. M.V.S. was involved in experimental design and reviewed the manuscript. K.A.N. was involved in experimental design, and reviewing and finalizing the manuscript.

\section{COMPETING INTERESTS}

The authors declare no conflict of interest.

\section{FUNDING}

This work was supported by the Schizophrenia Research Institute, using infrastructure funding from the New South Wales Ministry of Health. Tissues were received from the NSW Brain Tissue Resource Centre at the University of Sydney and the Sydney Brain Bank, which is supported by the National Health and Medical Research Council of Australia, The University of New South Wales, Neuroscience Research Australia, the Schizophrenia Research Institute and the National Institute of Alcohol Abuse and Alcoholism (NIH (NIAAA) R24AA012725). This study was supported by the Schizophrenia Research Institute in the form of the AM Wood Award for Schizophrenia Research, held by N.M.

\section{REFERENCES}

1. Tamminga, C. A., Stan, A. D. \& Wagner, A. D. The hippocampal formation in schizophrenia. Am. J. Psychiatry 167, 1178-1193 (2010).

2. Ranganath, C., Minzenberg, M. J. \& Ragland, J. D. The cognitive neuroscience of memory function and dysfunction in schizophrenia. Biol. Psychiatry 64, 18-25 (2008).

3. Carr, M. F. \& Frank, L. M. A single microcircuit with multiple functions: state dependent information processing in the hippocampus. Curr. Opin. Neurobiol. 22, 704-708 (2012).

4. Hall, J., Trent, S., Thomas, K. L., O'Donovan, M. C. \& Owen, M. J. Genetic risk for schizophrenia: convergence on synaptic pathways involved in plasticity. Biol. Psychiatry 77, 52-58 (2015).

5. Kim, E. \& Sheng, M. PDZ domain proteins of synapses. Nat. Rev. Neurosci. 5, 771-781 (2004).

6. Chen, X. et al. PSD-95 Is required to sustain the molecular organization of the postsynaptic density. J. Neurosci. 31, 6329-6338 (2011).

7. Ehrlich, I., Klein, M., Rumpel, S. \& Malinow, R. PSD-95 is required for activity-driven synapse stabilization. Proc. Natl Acad. Sci. USA 104, 4176-4181 (2007).

8. Ohnuma, T. et al. Gene expression of PSD95 in prefrontal cortex and hippocampus in schizophrenia. NeuroReport 11, 3133-3137 (2000).

9. Toyooka, K. et al. Selective reduction of a PDZ protein, SAP-97, in the prefrontal cortex of patients with chronic schizophrenia. J. Neurochem. 83, 797-806 (2002).

10. Kristiansen, L. V., Beneyto, M., Haroutunian, V. \& Meador-Woodruff, J. H. Changes in NMDA receptor subunits and interacting PSD proteins in dorsolateral prefrontal and anterior cingulate cortex indicate abnormal regional expression in schizophrenia. Mol. Psychiatry 11, 737-747 (2006).

11. Hammond, J. C., McCullumsmith, R. E., Haroutunian, V. \& Meador-Woodruff, J. H. Endosomal trafficking of AMPA receptors in frontal cortex of elderly patients with schizophrenia. Schizophr. Res. 130, 260-265 (2011).

12. Mueller, H. T., Haroutunian, V., Davis, K. L. \& Meador-Woodruff, J. H. Expression of the ionotropic glutamate receptor subunits and NMDA receptor-associated intracellular proteins in the substantia nigra in schizophrenia. Mol. Brain Res. 121, 60-69 (2004).

13. Kajimoto, Y. et al. Synapse-associated protein 90/postsynaptic density-95associated protein (SAPAP) is expressed differentially in phencyclidine-treated rats and is increased in the nucleus accumbens of patients with schizophrenia. Neuropsychopharmacology 28, 1831-1839 (2003).

14. Clinton, S. M. \& Meador-Woodruff, J. H. Abnormalities of the NMDA receptor and associated intracellular molecules in the thalamus in schizophrenia and bipolar disorder. Neuropsychopharmacology 29, 1353-1362 (2004).

15. Clinton, S. M., Haroutunian, V. \& Meador-Woodruff, J. H. Up-regulation of NMDA receptor subunit and post-synaptic density protein expression in the thalamus of elderly patients with schizophrenia. J. Neurochem. 98, 1114-1125 (2006).

16. Clinton, S. M., Haroutunian, V., Davis, K. L. \& Meador-Woodruff, J. H. Altered transcript expression of NMDA receptor-associated postsynaptic proteins in the thalamus of subjects with schizophrenia. Am. J. Psychiatry 160, 1100-1109 (2003).

17. Funk, A. J., Rumbaugh, G., Harotunian, V., McCullumsmith, R. E. \& MeadorWoodruff, J. H. Decreased expression of NMDA receptor-associated proteins in frontal cortex of elderly patients with schizophrenia. Neuroreport 20, 1019 (2009).
18. Beneyto, M. \& Meador-Woodruff, J. H. Lamina-specific abnormalities of NMDA receptor-associated postsynaptic protein transcripts in the prefrontal cortex in schizophrenia and bipolar disorder. Neuropsychopharmacology 33, 2175-2186 (2008).

19. Li, W. et al. Synaptic proteins in schizophrenia hippocampus indicate increased neuronal activity in CA3. Am. J. Psychiatry 172, 373-382 (2015).

20. McCullumsmith, R. E., et al. Decreased NR1, NR2A, and SAP102 transcript expression in the hippocampus in bipolar disorder. Brain Res. 1127, 108-118 (2007).

21. Toro, C. \& Deakin, J. F. W. NMDA receptor subunit NRI and postsynaptic protein PSD-95 in hippocampus and orbitofrontal cortex in schizophrenia and mood disorder. Schizophr Res. 80, 323-330 (2005).

22. Engmann, O. et al. Schizophrenia is associated with dysregulation of a Cdk5 activator that regulates synaptic protein expression and cognition. Brain 134 2408-2421 (2011).

23. Matosin, N. et al. Metabotropic glutamate receptor 5 , and its trafficking molecules Norbin and Tamalin, are increased in the CA1 hippocampal region of subjects with schizophrenia. Schizophr Res. 166, 212-218 (2015).

24. Hu, J. -H. et al. Presol dynamically regulates group I metabotropic glutamate receptors. Nat. Neurosci. 15, 836-844 (2012).

25. Lee, H. W. et al. Preso, a novel PSD-95-interacting FERM and PDZ domain protein that regulates dendritic spine morphogenesis. J. Neurosci. 28, 14546-14556 (2008).

26. Matosin, N. et al. Alterations of mGluR5 and its endogenous regulators Norbin, Tamalin and Preso1 in schizophrenia: towards a model of mGluR5 dysregulation. Acta Neuropathol. 130, 119-129 (2015).

27. Blanpied, T. A., Kerr, J. M. \& Ehlers, M. D. Structural plasticity with preserved topology in the postsynaptic protein network. Proc. Natl Acad. Sci. USA 105 12587-12592 (2008).

28. Sturgill, J. F., Steiner, P., Czervionke, B. L. \& Sabatini, B. L. Distinct Domains within PSD-95 mediate synaptic incorporation, stabilization, and activity-dependent trafficking. J. Neurosci. 29, 12845-12854 (2009).

29. Kitano, J. et al. Tamalin, a PDZ domain-containing protein, links a protein complex formation of group 1 metabotropic glutamate receptors and the guanine nucleotide exchange factor cytohesins. J. Neurosci. 22, 1280-1289 (2002).

30. Tu, J. C. et al. Coupling of mGluR/Homer and PSD-95 complexes by the shank family of postsynaptic density proteins. Neuron 23, 583-592 (1999).

31. Kitano, J. et al. Tamalin is a scaffold protein that interacts with multiple neuronal proteins in distinct modes of protein-protein association. J. Biol. Chem. 278 14762-14768 (2003).

32. Gupta, D. S. et al. Metabotropic glutamate receptor protein expression in the prefrontal cortex and striatum in schizophrenia. Synapse 57, 123-131 (2005).

33. Volk, D. W., Eggan, S. M. \& Lewis, D. A. Alterations in metabotropic glutamate receptor $1 \mathrm{a}$ and regulator of $\mathrm{G}$ protein signaling 4 in the prefrontal cortex in schizophrenia. Am. J. Psychiatry 167, 1489-1498 (2010).

34. Narr, K. L. et al. Regional specificity of hippocampal volume reductions in firstepisode schizophrenia. Neurolmage 21, 1563-1575 (2004).

35. Zierhut K. C. et al. Hippocampal CA1 deformity is related to symptom severity and antipsychotic dosage in schizophrenia. Brain 2013; 1-11.

36. Kawasaki, Y. et al. Regional cerebral blood-flow in patients with schizophreniaa preliminary-report. Eur. Arch. Psychiatry Clin. Neurosci. 241, 195-200 (1992).

37. Hu, W., MacDonald, M. L., Elswick, D. E. \& Sweet, R. A. The glutamate hypothesis of schizophrenia: evidence from human brain tissue studies. Ann. N Y Acad. Sci. 1338, 38-57 (2014).

38. Szumlinski, K. K., Kalivas, P. W. \& Worley, P. F. Homer proteins: implications for neuropsychiatric disorders. Curr. Opin. Neurobiol. 16, 251-257 (2006).

39. Zierhut, K. et al. The role of hippocampus dysfunction in deficient memory encoding and positive symptoms in schizophrenia. Psychiatry Res. Neuroimaging 183, 187-194 (2010)

40. Talati, P., Rane, S., Skinner, J., Gore, J. \& Heckers, S. Increased hippocampal blood volume and normal blood flow in schizophrenia. Psychiatry Res. 232, 219-225 (2015).

41. Schobel, S. A. et al. Differential targeting of the CA1 subfield of the hippocampal formation by schizophrenia and related psychotic disorders. Arch. Gen. Psychiatry 66, 938 (2009).

42. Gur, R. et al. Resting cerebral glucose-metabolism in first-episode and previously treated patients with schizophrenia relates to clinical-features. Arch. Gen. Psychiatry 52, 657-667 (1995).

43. Heckers, S. et al. Impaired recruitment of the hippocampus during conscious recollection in schizophrenia. Nat. Neurosci. 1, 318-323 (1998).

44. Fortin, D. A. et al. Live imaging of endogenous PSD-95 using ENABLED: a conditional strategy to fluorescently label endogenous proteins. J. Neurosci. 34 16698-16712 (2014).

45. Masliah, E., Terry, R. D., Alford, M. \& DeTeresa, R. Quantitative immunohistochemistry of synaptophysin in human neocortex: an alternative method to 
estimate density of presynaptic terminals in paraffin sections. J. Histochem. Cytochem. 38, 837-844 (1990).

46. Koffie, R. M. et al. Oligomeric amyloid $\beta$ associates with postsynaptic densities and correlates with excitatory synapse loss near senile plaques. Proc. Natl Acad. Sci. USA 106, 4012-4017 (2009).

47. Law, A. J., Weickert, C. S., Hyde, T. M., Kleinman, J. E. \& Harrison, P. J. Reduced spinophilin but not microtubule-associated protein 2 expression in the hippocampal formation in schizophrenia and mood disorders: molecular evidence for a pathology of dendritic spines. Am. J. Psychiatry 161, 1848-1855 (2004).

48. MacGillavry, H. D., Song, Y., Raghavachari, S. \& Blanpied, T. A. Nanoscale scaffolding domains within the postsynaptic density concentrate synaptic AMPA receptors. Neuron 78, 615-622 (2013).

49. Kaja, S. et al. Homer-1a immediate early gene expression correlates with better cognitive performance in aging. Age Dordr. Neth. 35, 1799-1808 (2013).

50. Segal, M. \& Korkotian, E. Endoplasmic reticulum calcium stores in dendritic spines. Front. Neuroanat. 8, 1-7 (2014).

51. Kammermeier, P. J. Endogenous homer proteins regulate metabotropic glutamate receptor signaling in neurons. J. Neurosci. 28, 8560-8567 (2008).

52. Saito, H., Kimura, M., Inanobe, A., Ohe, T. \& Kurachi, Y. An N-terminal sequence specific for a novel Homer1 isoform controls trafficking of group I metabotropic glutamate receptor in mammalian cells. Biochem. Biophys. Res. Commun. 296, 523-529 (2002).

53. Lisman, J. E. et al. Circuit-based framework for understanding neurotransmitter and risk gene interactions in schizophrenia. Trends Neurosci. 31, 234-242 (2008).

54. Heckers, S., Heinsen, H., Geiger, B. \& Beckmann, H. Hippocampal neuron number in schizophrenia: a stereological study. Arch. Gen. Psychiatry 48, 1002 (1991).

55. Konradi, C. et al. Hippocampal interneurons are abnormal in schizophrenia. Schizophr. Res. 131, 165-173 (2011).

56. Schmitt, A. et al. Stereologic investigation of the posterior part of the hippocampus in schizophrenia. Acta Neuropathol. 117, 395-407 (2009).

57. Walker, M. A. et al. Estimated neuronal populations and volumes of the hippocampus and its subfields in schizophrenia. Am. J. Psychiatry 159, 821-828 (2002).

58. Steiner, J. et al. GABAergic system impairment in the hippocampus and superior temporal gyrus of patients with paranoid schizophrenia: a post-mortem study. Schizophr. Res. 2016 Feb 24. pii: S0920-9964(16)30074-3. doi: 10.1016/j. schres.2016.02.018 (Epub ahead of print).

59. Zhang, Z. J. \& Reynolds, G. P. A selective decrease in the relative density of parvalbumin-immunoreactive neurons in the hippocampus in schizophrenia. Schizophr. Res. 55, 1-10 (2002).

60. Benes, F. M., Kwok, E. W., Vincent, S. L. \& Todtenkopf, M. S. A reduction of nonpyramidal cells in sector CA2 of schizophrenics and manic depressives. Biol. Psychiatry 44, 88-97 (1998).

61. Heckers, S. et al. Dlfferential hippocampal expression of glutamic acid decarboxylase 65 and 67 messenger RNA in bipolar disorder and schizophrenia. Arch. Gen. Psychiatry 59, 521-529 (2002).

62. Heckers, S. \& Konradi, C. GABAergic mechanisms of hippocampal hyperactivity in schizophrenia. Schizophr. Res. 167, 4-11 (2015).

63. Mannaioni, G., Marino, M. J., Valenti, O., Traynelis, S. F. \& Conn, P. J. Metabotropic glutamate receptors 1 and 5 differentially regulate CA1 pyramidal cell function. J. Neurosci. 21, 5925-5934 (2001).
64. Ferraguti, F. et al. Immunolocalization of metabotropic glutamate receptor 1a (mGluR1a) in distinct classes of interneuron in the CA1 region of the rat hippocampus. Hippocampus 14, 193-215 (2004).

65. Blackshaw, S. et al. Species, strain and developmental variations in hippocampal neuronal and endothelial nitric oxide synthase clarify discrepancies in nitric oxide-dependent synaptic plasticity. Neuroscience 119, 979-990 (2003).

66. Thompson, C. L. et al. Genomic anatomy of the hippocampus. Neuron 60 , 1010-1021 (2008).

67. Nithianantharajah, J. \& Hannan, A. J. Enriched environments, experiencedependent plasticity and disorders of the nervous system. Nat. Rev. Neurosci. 7, 697-709 (2006).

68. Vazdarjanova, A., McNaughton, B. L., Barnes, C. A., Worley, P. F. \& Guzowski, J. F. Experience-dependent coincident expression of the effector immediate-early genes arc and Homer 1a in hippocampal and neocortical neuronal networks. J. Neurosci. 22, 10067-10071 (2002).

69. Matosin N.. Exploring mGluR5 dysregulation in schizophrenia: from gene to protein. Available at: http://ro.uow.edu.au/theses/4439/. 2015. (accessed on 26 November 2015).

70. de Bartolomeis, A., Latte, G., Tomasetti, C. \& lasevoli, F. Glutamatergic postsynaptic density protein dysfunctions in synaptic plasticity and dendritic spines morphology: relevance to schizophrenia and other behavioral disorders pathophysiology, and implications for novel therapeutic approaches. Mol. Neurobiol. 49, 484-511 (2014).

71. Barr, A. M., Young, C. E., Phillips, A. G. \& Honer, W. G. Selective effects of typical antipsychotic drugs on SNAP-25 and synaptophysin in the hippocampal trisynaptic pathway. Int. J. Neuropsychopharmacol. 9, 457 (2006).

72. McCullumsmith, R. E., Hammond, J. H., Shan, D. \& Meador-Woodruff, J. H. Postmortem brain: an underutilized substrate for studying severe mental illness. Neuropsychopharmacology 39, 65-87 (2014).

73. Feyissa, A. M., Chandran, A., Stockmeier, C. A. \& Karolewicz, B. Reduced levels of NR2A and NR2B subunits of NMDA receptor and PSD-95 in the prefrontal cortex in major depression. Prog. Neuropsychopharmacol. Biol. Psychiatry 33, 70-75 (2009).

74. Weickert, C. S. et al. Selection of reference gene expression in a schizophrenia brain cohort. Aust. N Z J. Psychiatry 44, 59-70 (2010).

75. Fernandez-Enright, F., Andrews, J. L., Newell, K. A., Pantelis, C. \& Huang, X. F. Novel implications of Lingo-1 and its signaling partners in schizophrenia. Transl. Psychiatry 4, e348 (2014).

(c) This work is licensed under a Creative Commons Attribution 4.0
International License. The images or other third party material in this article are included in the article's Creative Commons license, unless indicated otherwise in the credit line; if the material is not included under the Creative Commons license, users will need to obtain permission from the license holder to reproduce the material. To view a copy of this license, visit http://creativecommons.org/licenses/ by/4.0/

(c) The Author(s) 2016

Supplementary Information accompanies the paper on the npj Schizophrenia website (http://www.nature.com/npjschz) 